\title{
Cell, Stem cells and Regenerative Medicine
}

\section{Isolation, Characterization and Application of BCR-ABL-ve Mesenchymal Stem Cells Derived from Peripheral Blood of Chronic Myeloid Leukemia (CML) in Enhancing Potentiality of Bone Marrow Transplantation in CML Patients}

\section{Pravin D Potdar* and Navjeet Kaur Lotey}

Department of Molecular Medicine \& Biology, Jaslok Hospital \& Research Centre, Mumbai, 400026, Maharashtra, India

"Corresponding author: Dr. Pravin D. Potdar, M.Sc, Ph.D, DMLT, DHE, DMS, Head, Department of Molecular Medicine \& Biology, Jaslok Hospital \& Research Centre, 15 Dr. G. Deshmukh Marg, Mumbai 400026, Maharashtra, India, Tel: 91-22-66573445; Fax: 91-22-23520508; E-mail: ppotdar@jaslokhospital.net or ppravin012@gmail.com
Received date: 04 May, 2015; Accepted date: 5 June, 2015; Published date: 12 June, 2015.

Citation: Potdar PD, Lotey NK (2015) Isolation, Characterization and Application of BCR-ABL-ve Mesenchymal Stem Cells Derived from Peripheral Blood of Chronic Myeloid Leukemia (CML) in Enhancing Potentiality of Bone Marrow Transplantation in CML Patients. Cell Stem Cells Regen Med 1(1): doi http://dx.doi.org/10.16966/2472-6990.101

Copyright: (C) 2015 Potdar PD et al. This is an open-access article distributed under the terms of the Creative Commons Attribution License, which permits unrestricted use, distribution, and reproduction in any medium, provided the original author and source are credited.

\begin{abstract}
Chronic Myeloid leukemia (CML) is a disorder causing uncontrolled growth of myeloproliferative blast cells. Tyrosine kinase inhibitors are not really useful in advanced stages and have their own side effects, reactions and resistance as well. Till date, CML can be fully cured only by bone marrow transplantation (BMT) which has its own limitations and thus need further studies to increase better survival of CML patients by this procedure. Our lab at Jaslok Hospital has been working on studying and characterizing mesenchymal stem cells in various types of hematological malignancies. We came up with a concept of isolating and characterizing mesenchymal stem cells (MSCs) from peripheral blood of a CML patient which can be used in combination with Bone Marrow Transplantation in the same CML patient. Our study has shown that the stem cells derived from peripheral blood of $C M L$ patient were found to be $B C R / A B L^{-v e}$. We designated this cell line as a "BCR/ABL"ve" cell line. Molecular characterization of these cells further confirmed their Mesenchymal phenotypes with distinct expression of CD105, CD13 and CD73 genes. Interestingly these cells also expressed pluripotency genes such as OCT4 and NANOG and cytokines i.e. IL6 and TNFa. We further confirmed the normal phenotype of BCR/ABL-ve MSCs by localizing expression of $\mathrm{H}-\mathrm{Ras}, \mathrm{Rb}, \mathrm{P} 53, \mathrm{P} 16$, P21, and EGFR and Ki67 cancer related proteins in these cells by immunofluorescence Microscopy and by in vitro transformation assay. Thus, we suggest that these normal BCR/ABL-ve MSCs derived from CML patient's peripheral blood can be used in addition to BMT procedure for a better recovery of CML disease in near future.
\end{abstract}

Keywords: Chronic myeloid leukemia; Mesenchymal stem cells; BCR/ABL; Pluripotent cells; Molecular markers; Stem cell transplantation

\section{Introduction}

Chronic Myeloid leukemia (CML) is a disorder of the myeloid lineage [1]. It accounts for almost $15 \%$ of all adult leukemias. It results in uncontrolled and abnormal growth of white blood cells referred to as blast cells. The disease progresses through three major stages i.e. chronic phase, accelerated phase and blast crisis phase which is decided on the number of blasts cells present in the patient's blood. If a patient is not treated at an early stage, the disease progresses to the second, third, accelerated and blast crisis phase respectively [2]. The actual trigger behind this progression is still not clearly understood. But, in most cases the reciprocal translocation mutation $\mathrm{t}$ [9:22] also known as Philadelphia chromosome results in a constitutively increase in tyrosine kinase activity due to this fusion BCR/ABL gene protein [3]. This constitutive expression of the fusion gene is the central target of this disease. FDA has approved certain drugs such as Imatinib (ST1571, Glivec from Novartis) which has now been established as a first line treatment for CML, generating full cytogenetic response in about majority of the patients in initial stage [4]. Similar drugs with improved mechanism of tyrosine kinase inhibition (TKI) have come up but none has been able to establish itself as a fully curative therapy. Most of the TKIs have not been much effective on patients at advanced stages. Patients with certain point mutations are resistant to these treatments [5-7]. It is only effective to inhibit the TK activity but not effective in eradicating the cancer stem cell subpopulations [8]. At such a condition, Bone Marrow Transplant (BMT) remains as the only known cure for this disease [9] but, it also has its own limitations.
Finding a suitable donor is one of the major problems in this therapy and patients also require crucial care to check graft vs. host reactions [10]. Hence, not all of the CML patients can be treated with allogeneic stem cell therapy, as it requires certain optimal conditions in patient's body. This has provoked scientists since long to establish autologous stem cell therapy (ASCT) as a full curative measure. ASCT could be used for children, older aged patients and those suffering from advanced form of this disease. It does not trigger adverse graft reactions and hence can be widely used for a variety of patients.

Our lab has been working in isolating mesenchymal stem cells from many hematological malignancies and it was found that the MSCs isolated in vitro, have shown non-malignant phenotypes or disease free genes [11]. MSCs are now recently looked upon as an alternative to overcome the problems associated with allogeneic HSCT by using them in combination with this established therapy [12-14]. We therefore propose to isolate mesenchymal stem cells from CML positive patient's peripheral blood and characterize those using specific molecular markers to understand its phenotypes and nature. As CML has the characteristic fusion of BCR/ $\mathrm{ABL}$ gene, we considered detecting these cells for $\mathrm{BCR} / \mathrm{ABL}$ transcript and also profile them for some common oncogenic markers. Apart from $\mathrm{BCR} / \mathrm{ABL}$, we also made use of several other oncogenic markers for profiling and characterizing these isolated cells to check for their normal phenotype by immunofluorescence, RT-PCR analysis and anchorage independent growth assay. If they are found to be normal and free from any abnormalities, these cells can be potentially useful along with BMT for better cure of this disease. 


\section{Materials and Methods}

\section{Sample collection}

CML patients' peripheral blood $(10 \mathrm{ml})$ was collected according to ethical guidelines of Jaslok hospital and Research Centre, Mumbai, India. Aliquots of cells were subjected to separation using Ficoll hypaque (Himedia, India) method. Intermediate layer was aspirated and transferred to $1.7 \mathrm{ml}$ Eppendorf tubes. Centrifugation was carried out at $4000 \mathrm{rpm}$ for 10 minutes to obtain pellet which was suspended in $1 \mathrm{ml}$ RPMI media, having $10 \%$ FBS, $0.2 \%$ Glutamine, $0.1 \%$ Insulin and $1 \%$ Pen Strep to obtain monolayer cell suspension which was cultured in $65 \mathrm{~mm}$ Nunc petri dishes and incubated overnight at $37^{\circ} \mathrm{C}$ with $5 \% \mathrm{CO}_{2}$ and at $90 \%$ humidity in $\mathrm{CO}_{2}$ incubator. Remaining part of plasma was used for RNA extraction as described below.

\section{Isolation of mesenchymal stem cells from peripheral blood of CML patient}

The cells suspended in above growth media were incubated at $37^{\circ} \mathrm{C}$ with $5 \% \mathrm{CO}_{2}$ at $90 \%$ humidity in $\mathrm{CO}_{2}$ incubator as described above. The adherent cells were washed with $1 \mathrm{X}$ PBS and fed with DMEM medium with $10 \%$ FBS, $0.2 \%$ Glutamine, $0.1 \%$ Insulin and $1 \%$ Pen Strep. These cells were observed every day for their growth and photographed using camera attached to phase contrast microscope. These cells became confluent within 20 days of culture. After confluency cells were trypsinized with $0.25 \%$ PBS-Trypsin for further amplification in several $65 \mathrm{~mm}$ flasks, these cells were then frozen at $-85^{\circ} \mathrm{C}$ till further experimentation. Some part of these cells were processed for RNA extraction by Trizol method and used for gene expression study.

\section{Phase contrast microscopy}

The growth, proliferation and external morphological features of cells were inspected using Phase Contrast Microscope (Carl Zeiss Co.) and the images were documented progressively with the help of attached camera and TS view software. The observations were made under $20 \mathrm{X}$ and $40 \mathrm{X}$ magnifications.

\section{Light microscopy}

For observation under compound light microscope, $1 \times 10^{5}$ cells per ml were grown on sterile cover slips till they reached sub confluent level. Giemsa staining was carried out to study and observe phenotypic characteristics of these cells. The cells on the cover slip were washed using 1XPBS and fixed using 50\% methanol for 10 minutes. Filtered Giemsa stain (Fischer Scientific') was used for staining the cells for about 10 minutes. The excess stain was washed with distilled water and cover slip was allowed to air dry before observing under light microscope using 20X and 40X magnifications.

\section{Immunofluorescence microscopy}

For preparing the cells to be used for immunofluorescence, we cultured $1 \times 10^{5}$ cells per $\mathrm{ml}$ on sterile cover slips. On having partial confluency, the cells were flooded with blocking buffer for about half an hour and then were fixed using $4 \%$ paraformaldehyde. We selected 7 oncogenic antibodies viz. H-Ras, p53, Rb gene, Waf1, p16, EGFR and Ki-67 which are typically observed in tumor cells. Primary antibody at 1:10 dilution in blocking buffer was added after washing these cells with 1X PBS and incubated for 2 hours. FITC labeled Goat anti-mouse IgG was used as a common Secondary antibody at a 1:100 dilution in 1X PBS under dark condition with all the primary antibodies. It was added after washing primary antibody with 1 X PBS and incubated for 2 hours in dark. The cover slip was washed, dried and inverted on a glass slide with mounting media, Fluromount (Sigma Aldrich, USA). The edges of the cover slip were fixed with nail polish and then subjected to observation under Phase Contrast Microscopy with fluorescent attachment for FITC excitation and the images were photographed and documented.

\section{Anchorage independent assay}

Mixture of $0.4 \%$ soft gel was prepared using $0.8 \%$ agarose solution added in equal volume of double strength RPMI media containing $20 \%$ FBS, 2\% Penstrep and 0.4\% Glutamine. The solution was cooled upto $40^{\circ} \mathrm{C}$ and $1.5 \mathrm{ml}$ each was poured on $35 \mathrm{~mm}$ Nunc culture dishes. Sub confluent culture of cells were trypsinised with $0.25 \%$ PBS-Trypsin and monolayer cells suspension was prepared in the above growth medium having density of $1 \times 10^{4}$ cells per $\mathrm{ml}$. This suspension was poured on the soft agar layered culture dishes. Cells were observed and fed with $0.5 \mathrm{ml}$ RPMI containing 10X FBS, $1 \%$ Penstrep and $0.2 \%$ glutamine $2-3$ times per week for 2 weeks. After two weeks, we observed the colonies of the cells appeared on agar plate sand documented them in photographs taken under phase contrast microscope.

\section{Molecular markers}

Total RNA was extracted using Trizol" (Sigma Aldrich, USA) method. $2 \mu \mathrm{g}$ of RNA was transcribed to cDNA using Applied Biosystems $s^{\circ}$ High Capacity cDNA Kit. We selected various markers for characterization of this cell line. Primer sequences and PCR conditions for BCR/ABL, CD 105, CD 13, CD 73, CD 34, CD 45, OCT 4, NANOG, SOX 2, LIF, Keratin 18, TNFa, IL 6, Dap Kinase, EGFR and housekeeping gene $\beta$ Actin have been previously reported by our lab $[15,16]$. In addition, we also profiled 3 new markers for the CML cells viz. Bcl-2, cMyc and Notch2 and PCR conditions were common for all these three genes starting with initial denaturation at $95^{\circ} \mathrm{C}$ for 5 minutes, followed by 35 cycles at $94^{\circ} \mathrm{C}$ for 30 seconds, $60^{\circ} \mathrm{C}$ for 30 seconds and $72^{\circ} \mathrm{C}$ for 1 minute. Primer sequences of these genes have been described below (Table 1).

\section{Results}

\section{Isolation of adherent cells derived from CML patient's peripheral blood}

We have earlier described in this manuscript about the culturing of cancer patient derived stem cells. Some of the Ficoll isolated suspension cells from peripheral blood of CML patient were found to be adhered to the bottom of the culture dishes within 2-3 days of culture as shown in Figure 1a. These cells then proliferated very quickly and reached confluency within 20-30 days of culture as shown in Figure 1b. After confluency, these cells were trypsinised with $0.25 \%$ PBS- Trypsin and suspended in a fresh growth medium \& initially plated on Nunc $35 \mathrm{~mm}$ culture dish for further growth. On attaining confluency, these cells were divided to create further passages by repeating trypsinization process as described before. Some cells in the culture were observed to form pluripotent clones in the succeeding passages as shown in Figure 1c. Thus a stable cell line was developed and grew in many passages. These cells were then subjected to phenotypic and genotypic characterization to better understand their cellular and molecular characteristics.

\section{Giemsa staining}

Giemsa staining was carried out for observation of phenotypic characters of the cells. A network of fiber like structure was observed

\begin{tabular}{|l|l|l|}
\hline \multicolumn{1}{|c|}{ Gene } & \multicolumn{1}{|c|}{ Forward Primer } & \multicolumn{1}{c|}{ Reverse Primer } \\
\hline Bcl 2 & TTATCCAGCAGCTTTTCGG & GGCGGCAGATGAATTACAA \\
\hline c Myc & GCCTCAGAGTGCATCGAC & TCCACAGAAACAACATCG \\
\hline Notch2 & ACTTCCTGCCAAGCATTCC & GTCCATGTCTTCAGTGAGAAC \\
\hline
\end{tabular}

Table 1: It shows primer Sequences for Bcl 2, cMyc and Notch2 genes used in our experiments. 


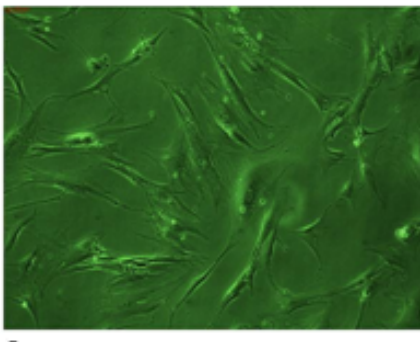

a
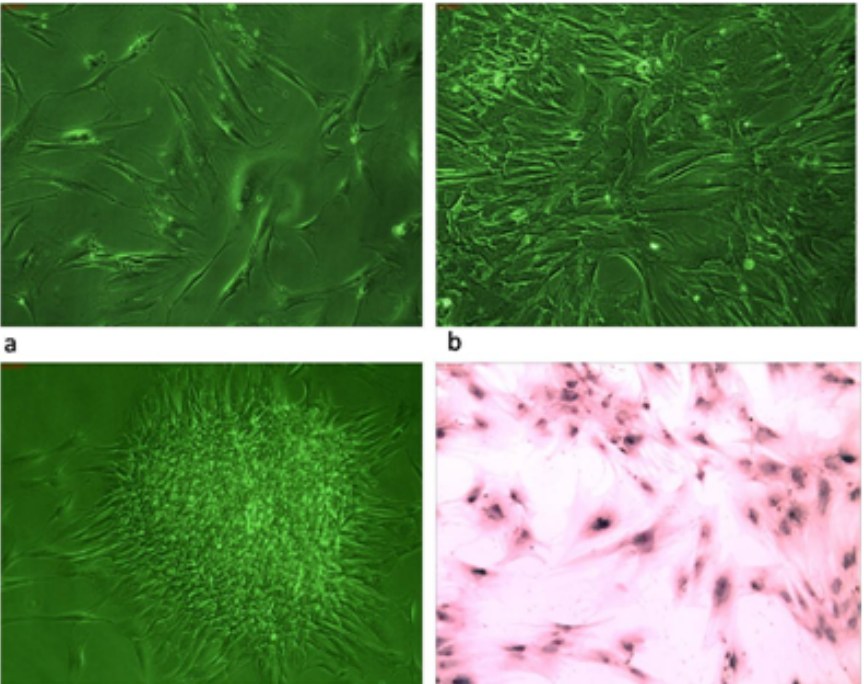

b

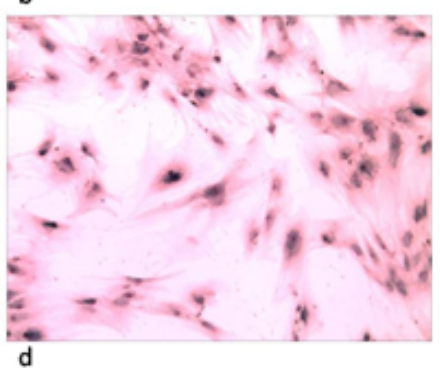

Figure 1a-1d: It shows phase and light microscopic pictures of MSCs cell line developed from peripheral blood cells of CML patients. Figure $1 \mathrm{a}$ shows adherent cells at day 5 of this culture, figure $1 \mathrm{~b}$ shows well grown confluent cells figure 1c shows pluripotency clone obtained after 10 passages \& figure d shows Giemsa stained cells with elongated morphology.

around the nucleus connecting it to the cytoplasm. Most of the cells were very elongated and showed two to three nucleoli in their nucleus. Some cells were slender and small in size whereas, some were very large and spreaded. Some cells showed presence of numerous fine filopodia which, could be noticed after careful observation of the stained cells under high magnification. Figure 1d shows Giemsa stained picture of these cells.

\section{Expression of BCR/ABL gene in the isolated stem cells from} CML patient

Molecular marker profiling was carried out to find out presence or absence of certain relevant genes which help in revealing genetic characters of these cells. BCR/ABL is the fusion gene resulting from [9:22] translocation. Hence, identifying presence of this gene is of utmost importance for cells derived from CML patient. Figure 2 shows the expression of BCR/ABL gene in the patient's blood plasma cells called as "in vivo" cells and cells derived in cultures are called as "in vitro" cells at passage 3 and passage 4 . It can be seen that the BCR/ABL gene is present in blood plasma cells (in vivo cells) but absent in both the cell lines (In vitro) at passage 3 and 4 indicating that these cells are growing without $\mathrm{BCR} / \mathrm{ABL}$ fusion protein. We therefore, designated these cells as BCR/ $\mathrm{ABL}^{-\mathrm{ve}}$ cells and carried out their further characterization.

\section{Anchorage independent growth assay}

Anchorage independent or soft agar assay is mainly used to study in vitro transformation of the cells growing in culture. Figure 3 shows an individual assay for $\mathrm{BCR} / \mathrm{ABL}^{-\mathrm{ve}}$ cells. It can be clearly seen that these cells formed very few anchorage independent colonies by the end of second week indicating that most of these cells have normal phenotype which is further confirmed by our studies on cancer molecular markers by RT/ PCR as well as by immunofluorescence Microscopy.

\section{Expression of mesenchymal and hematopoietic markers in} $\mathrm{BCR} / \mathrm{ABL}^{-\mathrm{ve}}$ cell line

Stem cells can be characterized for their mesenchymal and hematopoietic phenotypes using specific molecular markers. Figure 4 shows expression of

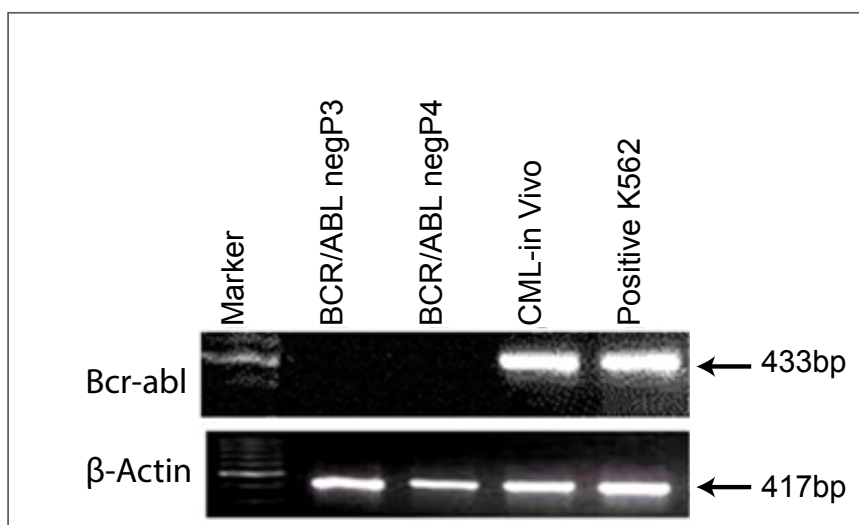

Figure 2: It shows the expression of BCR-ABL gene in "in vivo"cells but absent in "in vitro" cells of CML patient.

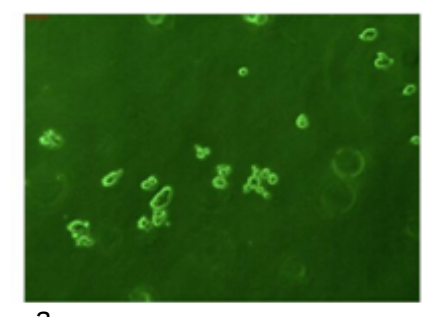

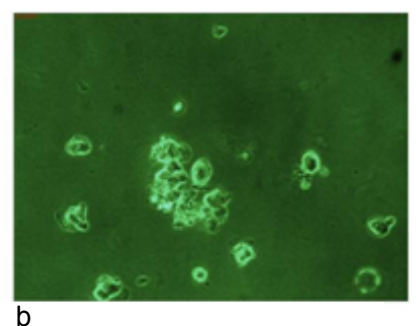

Figure 3: It shows an anchorage independent growth assay (soft agar assay) for BCR/ABL-ve cells. No proper colonies were found on soft agar assay even after 2 weeks of plating these cells.

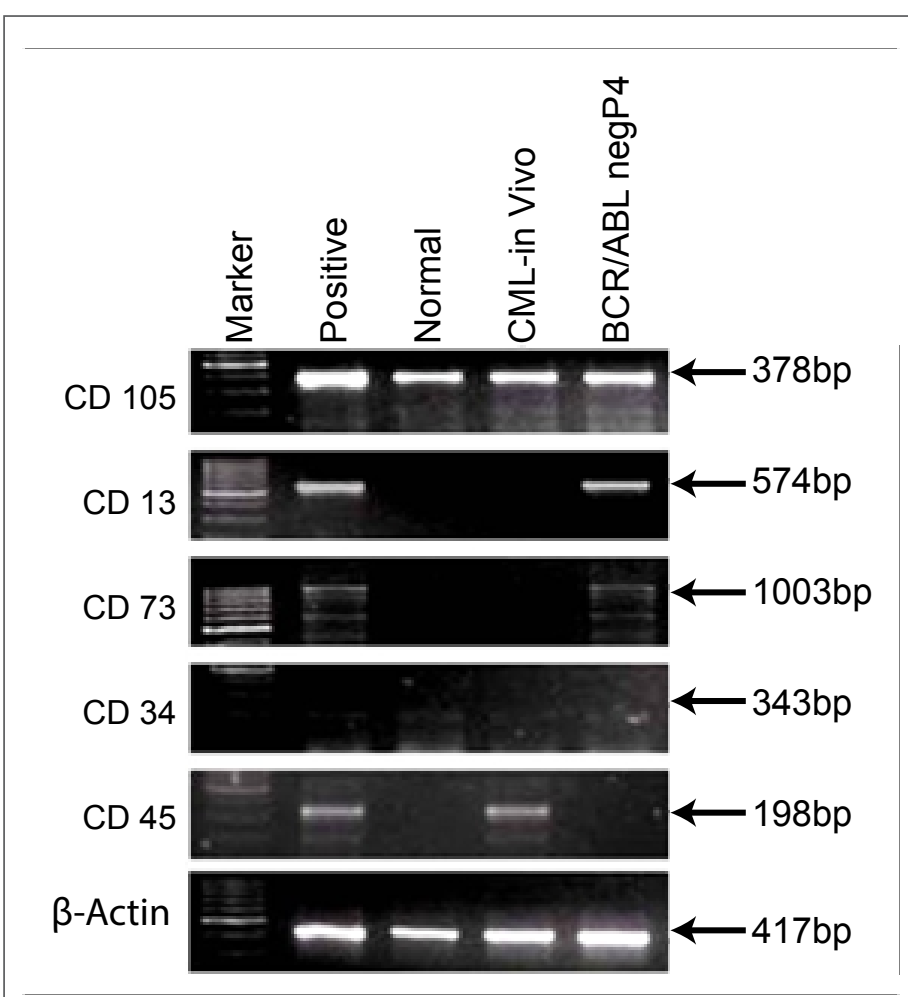

Figure 4: It shows Mesenchymal (CD105, CD13 \& CD73) and Hematopoietic (CD34 \& CD45) Markers for BCR/ABL-ve cells and CML patient's blood plasma cells i.e in vivo cells.

Citation: Potdar PD, Lotey NK (2015) Isolation, Characterization and Application of BCR-ABL-ve Mesenchymal Stem Cells Derived from Peripheral Blood of Chronic Myeloid Leukemia (CML) in Enhancing Potentiality of Bone Marrow Transplantation in CML Patients. Cell Stem Cells Regen Med 1(1): doi http://dx.doi. org/10.16966/2472-6990.101 
mesenchymal and hematopoietic markers in $\mathrm{BCR} / \mathrm{ABL}^{-\mathrm{ve}}$ cells at early passage $\mathrm{P} 4$. The $\mathrm{BCR} / \mathrm{ABL}^{-v e}$ cells showed presence of $\mathrm{CD} 105, \mathrm{CD} 13$ and CD73 genes indicating their mesenchymal phenotypes whereas, CML patient's in vivo cells showed only presence of CD 105 and absence of CD13 and CD73 genes. The reason for this absence is not known. It was also seen that $\mathrm{BCR} / \mathrm{ABL}^{\text {ve }}$ cells mildly expressed $\mathrm{CD} 34$ gene at early passage and diminished after few more passages. These cells did not express CD45 gene which is another prominent gene marker for hematopoietic cells. Therefore, absence of CD 45 gene in BCR/ABL-ve cells confirmed their Mesenchymal phenotype. Thus, we can confirm that the BCR/ABL-ve cells are mesenchymal stem cells derived from peripheral blood of CML patients with mild expression of CD34 gene at early passage which is generally vanished after several passaging of these cells in culture.

\section{Expression of pluripotency markers in $\mathrm{BCR} / \mathrm{ABL}^{-\mathrm{ve}}$ cell line}

Pluripotency is one of the characteristic properties of stem cells. In figure 5, we showed the expression of Oct4, Nanog and Sox 2 genes in $\mathrm{BCR} / \mathrm{ABL}^{-\mathrm{ve}}$ cells and in CML patient's blood cells (in vivo). It was shown here that both in vivo cells of CML patient as well as $\mathrm{BCR} / \mathrm{ABL}^{-v e}$ cell line showed presence of OCT4 and Nanog genes confirming their pluripotent nature.

\section{Expression of differentiation markers in $\mathrm{BCR} / \mathrm{ABL}^{\text {-ve }}$ cell line}

Differentiation is a stage where the stem cells determine themselves into a particular phenotype. Figure 6 shows differentiation markers which reveal presence of LIF and Keratin in both in vivo CML cells and $\mathrm{BCR} / \mathrm{ABL}^{-\mathrm{ve}}$ cells which indicate that the $\mathrm{BCR} / \mathrm{ABL}^{-\mathrm{ve}}$ cells maintain undifferentiated and epidermal state in culture as it is in vivo. LIF mainly helps to keep undifferentiated status whereas; Keratin expression indicates the epidermal character of these cells.

\section{Expression of cytokines markers in $\mathrm{BCR} / \mathrm{ABL}^{-\mathrm{ve}}$ cell line}

Cytokines are prognostic markers for many disease conditions. Figure 7 shows the expression of TNFa and IL6 in both in vivo and BCR/ABL-ve cells. It was shown that TNFa was expressed in both cell types whereas, IL6 was only present in $\mathrm{BCR} / \mathrm{ABL}^{-v e}$ cells and was absent in CML patient's in vivo cells.

\section{Expression of various oncogenic markers in $\mathrm{BCR} / \mathrm{ABL}^{-\mathrm{ve}}$ cell line}

As we have aimed to use these cells for transplantation purpose along with BMT, we need to check this BCR/ABL-ve cell line for any oncogenic abnormalities exist through previous disease cells. To confirm this, we have chosen specific oncogenic markers such as Dap kinase, Bcl2, Notch, cMyc and EGFR genes for this study. Figure 8 displays the results of various oncogenic markers which were used to profile the $\mathrm{BCR} / \mathrm{ABL}^{-v e}$ cells at passage 3 (P3) and passage 4 (P4). It was observed that Dap kinase, $\mathrm{Bcl} 2$ and Notch2 genes were present in both in vivo and $\mathrm{BCR} / \mathrm{ABL}^{-v e}$ cells whereas, cMyc and EGFR were found to be absent in both in vivo as well as $B C R / A B L^{-v e}$ cells indicating their normal phenotypes and did not have any oncogenic abnormality. Thus this $\mathrm{BCR} / \mathrm{ABL}^{-\mathrm{ve}}$ cells can be used for transplantation program along with BMT process for better cure of this disease.

\section{Immunofluorescence microscopy localized oncogenic markers in $\mathrm{BCR} / \mathrm{ABL}^{-\mathrm{ve}}$ cell line}

Immunofluorescence is a tool used to identify presence and localization of proteins in the given cells. We have studied localization of specific oncogenic, tumor suppressor, nucleolus and surface receptor proteins in $\mathrm{BCR} / \mathrm{ABL}^{-v e}$ cells to confirm their normal phenotype by immunofluorescence microscopy.

Figure 9A shows the presence of expression of H-Rasoncoprotein in most of the BCR/ABL-ve cells cytoplasm. Similarly all the tumor suppressor

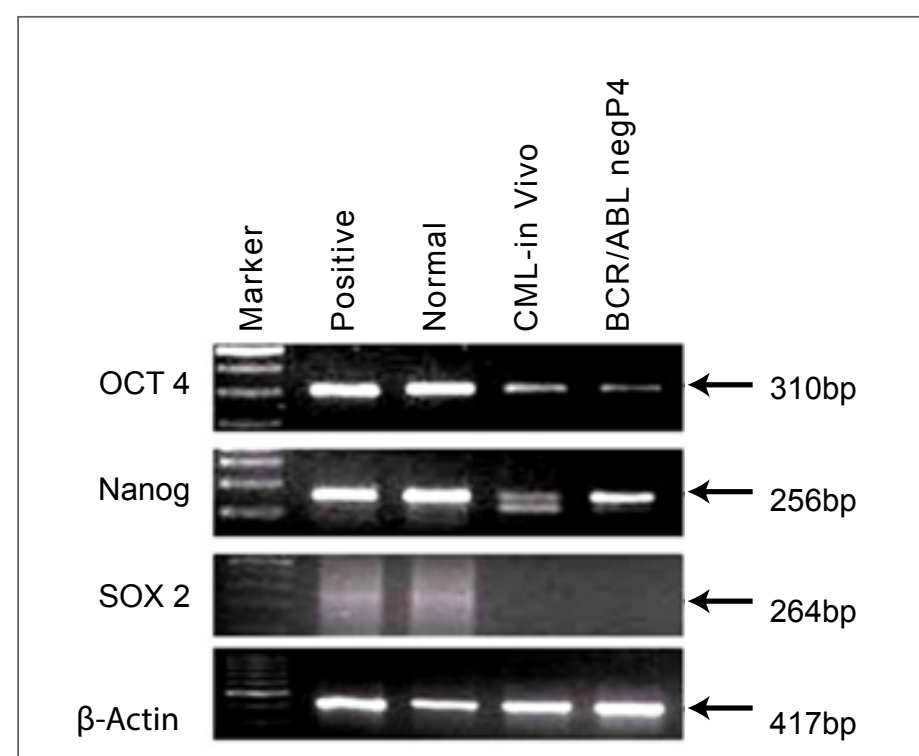

Figure 5: It shows pluripotency makers, OCT4, NANAOG \& SOX2 in $\mathrm{BCR} / \mathrm{ABL}$-ve cells and CML patient's blood cells

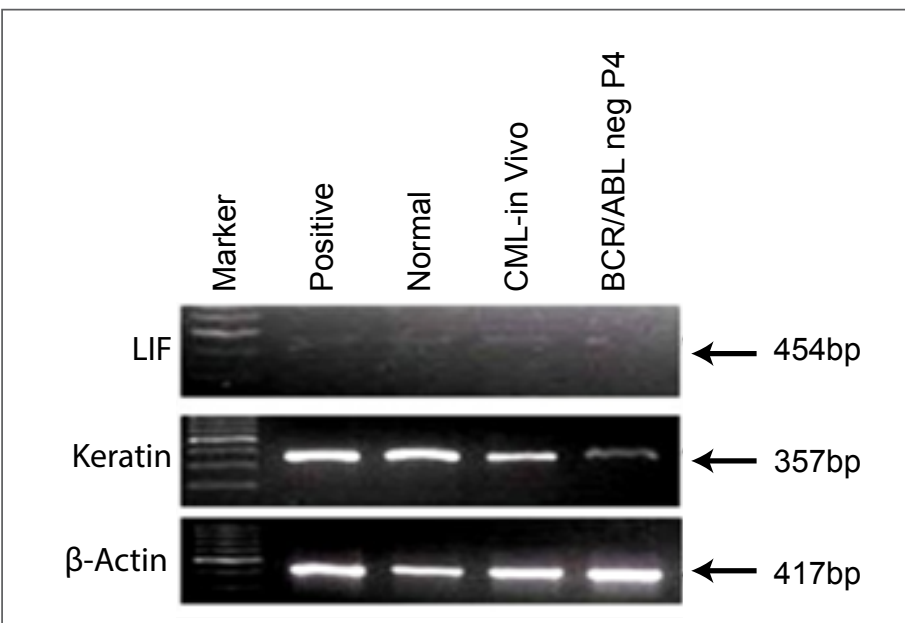

Figure 6: It shows differentiation markers, LIF and Keratin in BCR/ $A B L-v e$ cells and CML patient's blood cells

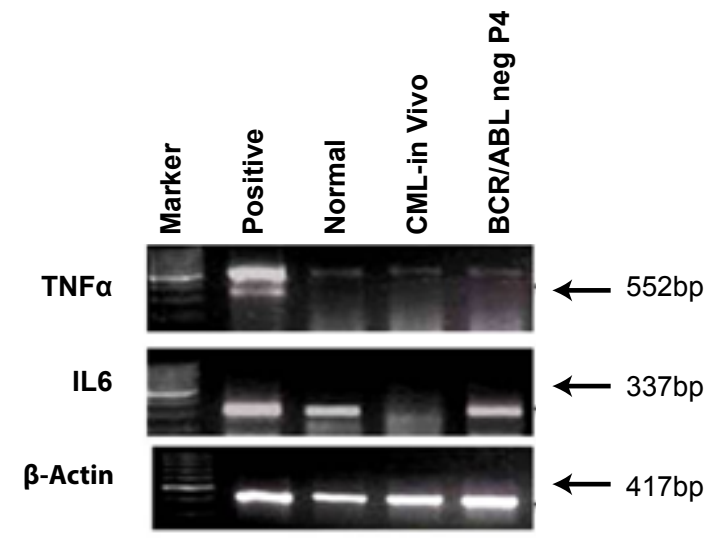

Figure 7: It shows cytokine markers, IL6 and TNFa and Keratin in BCR/ABL-ve cells and CML patient's blood cells

Citation: Potdar PD, Lotey NK (2015) Isolation, Characterization and Application of BCR-ABL-ve Mesenchymal Stem Cells Derived from Peripheral Blood of Chronic Myeloid Leukemia (CML) in Enhancing Potentiality of Bone Marrow Transplantation in CML Patients. Cell Stem Cells Regen Med 1(1): doi http://dx.doi. org/10.16966/2472-6990.101 
proteins such as p53, Rb, p16 \& p21 were present in almost all these cells. p53 was observed throughout the cell's structure and present in both nuclear as well cytoplasmic region as shown in Figure 9C. Retinoblastoma protein $(\mathrm{Rb})$ and p16 genes were present in nuclear region only as shown in Figures 9B and 9E respectively. In p16 staining, nucleolus remained unstained while rest of nucleus was stained prominently. Whereas, p21 protein was found to be present in some organelle like structure below the nucleus (Figure 9 D).

A very small percentage of cells showed fluorescence with antigens Ki67 and EGFR. Ki-67 was found to be present exclusively in the nucleolus which has been shown in Figure 10A whereas, EGFR was absent in BCR/ $\mathrm{ABL}^{\text {-ve }}$ cells as shown in Figure 10B.

So overall immunofluorescence studies confirmed normal phenotypes of $\mathrm{BCR} / \mathrm{ABL}^{-v e}$ cell line and thus these cells can be used for transplantation studies in combination with BMT for cure of this disease in near future.

\section{Discussion}

Chronic myeloid leukemia is a progressive disorder of the stem cells, whose only cure in the blast crisis stage is a BMT which requires HLA matched allogenic donors for HSCT. In this condition, its availability and transplant-associated complications make it a vexed procedure. Hence this disorder along with many others still awaits an ideal cure with minimal side effects. MSCs are being looked upon as new therapeutic agents for a number of diseases including hematological malignancies [12-14]. MSCs in co-transplants with umbilical cord stem cells or hematopoietic stem cells have given positive results. The biggest benefit in choosing MSCs for autologous or allogeneic transplant is reduction or complete evasion from graft vs. host reactions. They are also known to improve the efficiency of hematopoietic transplants. Hence, we channelized our study to develop MSCs from peripheral blood of CML patient and characterized them for normal phenotype using various biomarkers by RT/PCT and Immunofluorescence microscopy.

Our lab at Jaslok hospital and research centre has been working on isolating, characterizing and culturing of stem cells from many cancer tumors and hematological malignancies [11]. We considered isolating

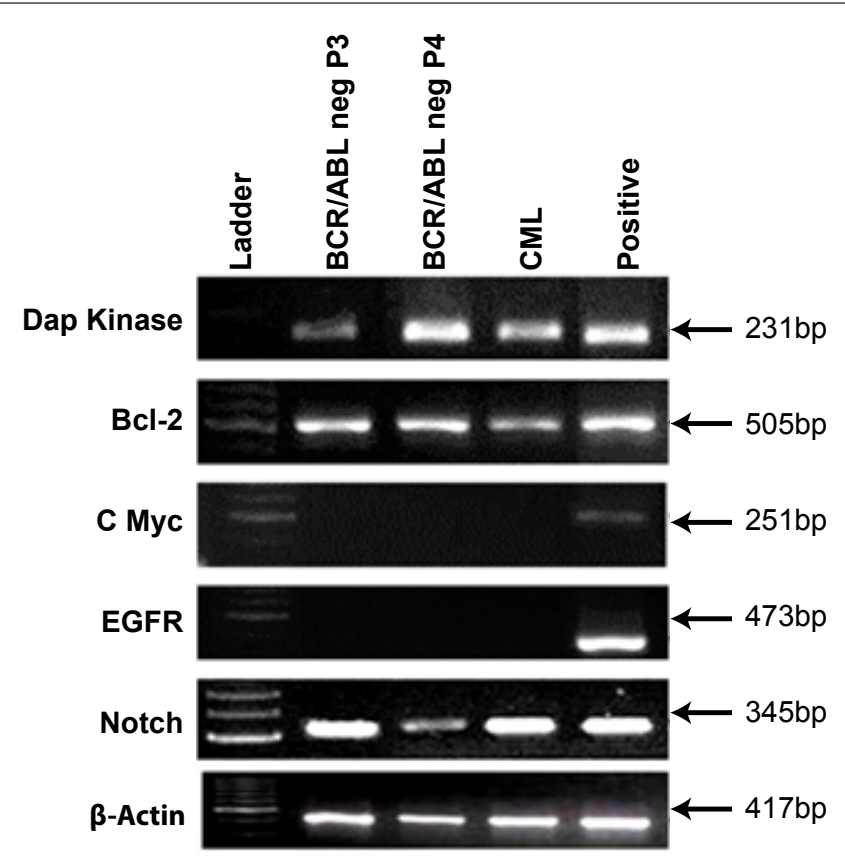

Figure 8: It shows oncogenic markers, DAPK, BCL2, cMYC, EGFR \& $\mathrm{NOTCH} 2$ in BCR/ABL-ve cells and CML patient's blood cells.

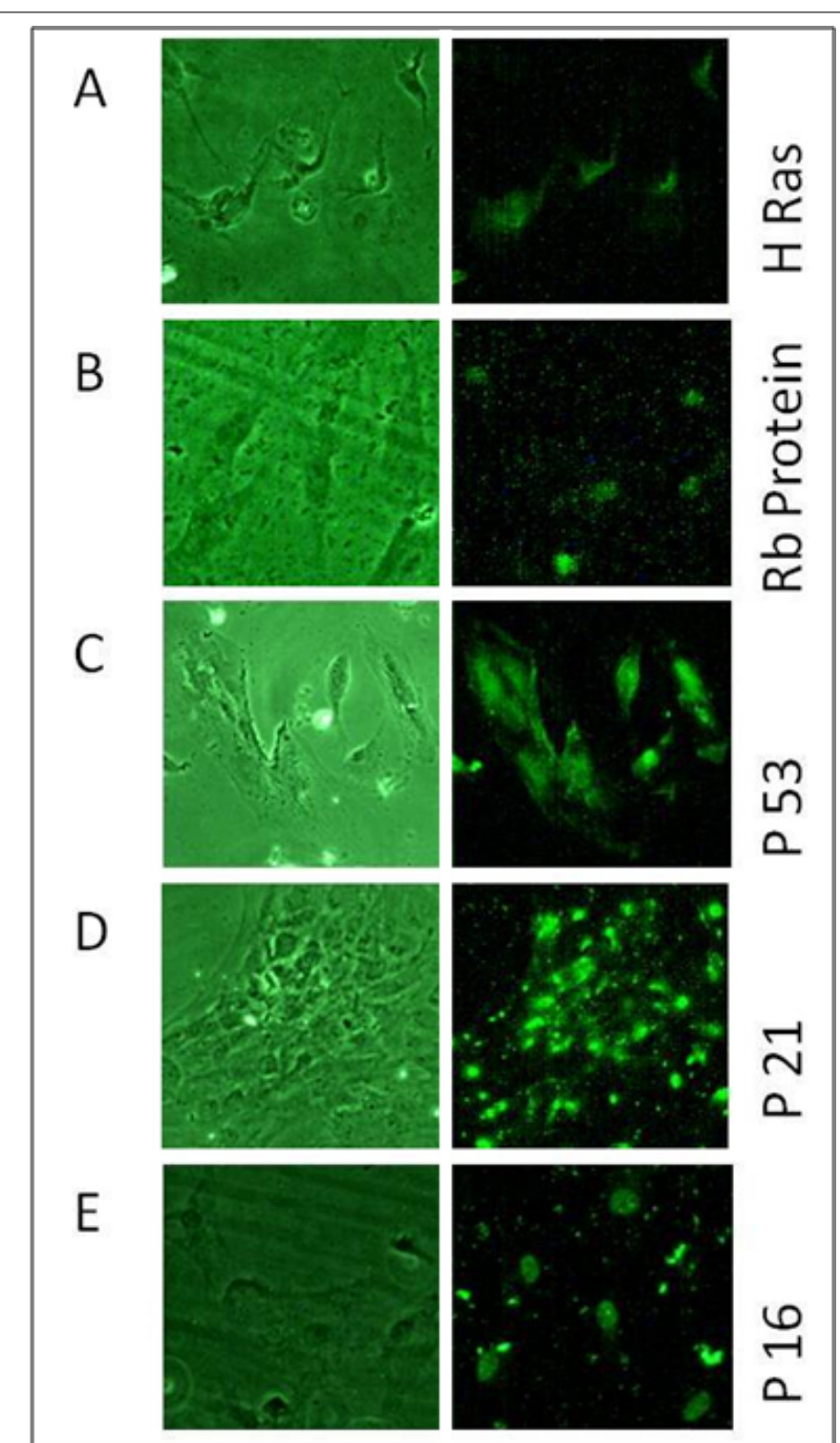

Figure 9: It shows Immunofluorescence microscopy for A) HRas, B) $\mathrm{Rb}$ C) P53, D) P21\& E) P16oncoproteins in BCR-ABL-ve cells

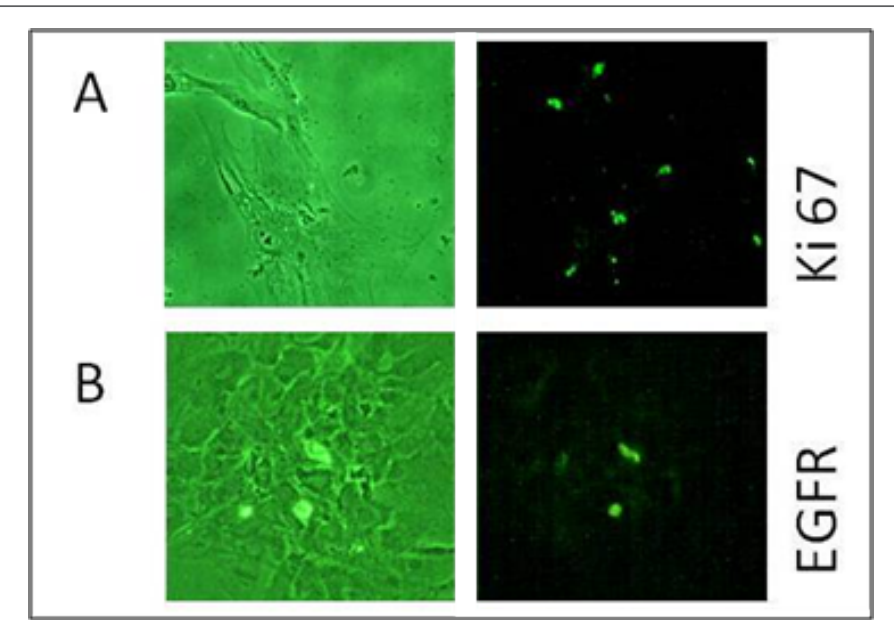

Figure 10: It shows Immunofluorescence microscopy for A) Ki67 \& B) EGFR oncoproteins in BCR-ABL-ve cells

Citation: Potdar PD, Lotey NK (2015) Isolation, Characterization and Application of BCR-ABL-ve Mesenchymal Stem Cells Derived from Peripheral Blood of Chronic Myeloid Leukemia (CML) in Enhancing Potentiality of Bone Marrow Transplantation in CML Patients. Cell Stem Cells Regen Med 1(1): doi http://dx.doi. org/10.16966/2472-6990.101 
stem cells from CML patients and to study their phenotypic characters and molecular mechanism to see whether, these stem cells are safe enough to be used for autologous stem cell transplantation in combination with BMT. We further assessed these stem cells for presence or absence of $\mathrm{BCR} / \mathrm{ABL}$ transcript and we found that cells isolated and grown from $\mathrm{CML}$ patients were $\mathrm{BCR} / \mathrm{ABL}^{\text {-ve }}$ cells and therefore we designated these cells as $\mathrm{BCR} / \mathrm{ABL}^{-\mathrm{ve}}$ cell line. A similar study was carried out by Carrara et al. [17] and our results are obtained in concordance with them. Upon establishment of the BCR/ABL ${ }^{-v e}$ cell line and thorough observation of phenotypic characters through phase contrast microscopy and Giemsa staining, we could taper down to the idea of presence of mesenchymal stem cells. To reassert this opinion, we subjected the cells to certain specific stem cell markers, which confirmed our conjecture. Molecular profiling of these cells with expression of CD105, CD13, and CD73 affirmed the mesenchymal character of these cells. OCT4 and NANOG activity indicate presence of pluripotent character in these cells [15]. Expression of LIF is indicative of undifferentiated state of these cells whereas, keratin which is distinctly expressed is used for identifying epithelial nature of cells [15]. However, expression of CD34 was also found in these cells whose presence is generally considered as a negative marker for MSCs. In our study we detected expression of CD34 at early passage cells and therefore we got weak expression of CD34 in these cells. However, CD45 which is another marker for hematopoietic cell was completely absent in these cells indicating that $\mathrm{BCR} / \mathrm{ABL}^{-\mathrm{ve}}$ cells are mesenchymal stem cells only. The CD34 expression seen in BCR/ABL-ve cells may vanish after few more passage. Diminishing of CD34 gene has been well reported by Lin et al. [18]. This could be explained with the help of some previous findings that, peripheral blood derived cells may show presence ofCD34 and also indicate that they are a part of vasculature. CD $34^{+}$MSCs have also been reported to show numerous filopodia and that, CD34 is present at the tips of these filopodia for promoting angiogenesis. Observance of numerous filopodia in some of the cells has been reported in the results above which probably support the presence of CD $34^{+}$MSCs in our culture. Also, weak presence of $\mathrm{CD} 34$ has been reported in early passages of peripheral blood derived MSCs which rapidly diminishes in the following passages. Since we have assessed only an early passage, there are chances of observing mild presence of CD34 [19-21].

We further used several oncogenic markers and in vivo transplantation assay to reconfirm normal phenotype of these cells. We selected 5 oncogenic markers viz. Dap Kinase, Bcl-2, cMyc, EFGR \& NOTCH2 to confirm their presence or absence in these cells by RT/PCR analysis. Dap kinase is known to be a potential tumor suppressor gene and absence of this gene expedient the growth of cells to form tumor [22]. Our cells showed presence of Dap kinase gene clearly indicating normal phenotype of BCR/ $\mathrm{ABL}^{-v e}$ cells. It is reported that high expression of cMyc causes aggravated expression of cancerous genes [23]. Our cells showed absence of oncogene $\mathrm{cMyc}$ indicating a normal type again. Deregulation in the signaling of Notch2 can be a cardinal event in many types of hematological disorders [24]. Deregulation often leads to reduction in the expression of this gene. Our BCR/ABL ${ }^{-v e}$ cells showed presence of Notch2, which is again a normal cell characteristic. EGFR is a cell surface receptor belonging to EGF family. It has also been reported in certain cases that increased expression of EGFR, promotes the ability of cancer cells to metastasize and hence many drugs are focused on down regulation of EGFR to control the cancer [25]. The BCR/ABL ${ }^{\text {ve }}$ cells showed no expression EGFR in these cells indicating confirmed normal phenotype of $\mathrm{BCR} / \mathrm{ABL}^{-v e}$ cells. We know that there is no role of EGFR in causation of CML but we have checked this expression in MSCs isolated from peripheral blood of CML patients, just to check this important cancer causing gene in these cells. Recently we have shown that many of mesenchymal stem cell lines grown in culture are secreting Il-6 cytokines [11]. In our study, BCR/ABL ${ }^{-v e}$ mesenchymal stem cells secrete significant amount of IL-6 and therefore there is an added advantage if they are considered for autologous transplantation in combination with BMT to cure CML. Whereas, TNFa and Bcl-2 have been shown to be expressed normally indicating normal phenotype of $\mathrm{BCR} / \mathrm{ABL}^{-\mathrm{ve}}$ cells.

We also performed Immunofluorescence to detect presence and absence of certain oncogenic proteins to confirm normal phenotypes of $\mathrm{BCR} / \mathrm{ABL}^{-\mathrm{ve}}$ cells. In this study, we observed that very few $\mathrm{BCR} / \mathrm{ABL}^{-\mathrm{ve}}$ cells showed EGFR protein thus indicating normal phenotype. Similarly $\mathrm{H}$-Ras, an oncogenic marker was present in almost all of the BCR/ABL ${ }^{-v e}$ cells. High expression of $\mathrm{H}$-Ras genes along with Waf1 can inhibit proliferation of K562 cells in vitro. BCR/ABL ${ }^{\text {ve }}$ cells have shown presence of both of these genes which help in supporting the normal phenotype of these cells $[26,27]$. P53 is a well-known tumor suppressor gene and is often down regulated by $\mathrm{BCR} / \mathrm{ABL}$ activity [28]. As $\mathrm{BCR} / \mathrm{ABL}$ is not detected in these cells, it was expected to observe presence of this protein in cells. As per our expectations, almost all of these cells showed bright and distinct presence of p53 throughout the cell and its nucleus. It has also been reported in some cases that restoration of $\mathrm{p} 53$ gene can initiate apoptosis in leukemic cells as well as increase the proliferation of normal type of cells. We have also studied $\mathrm{Rb}$ protein expression in $\mathrm{BCR} / \mathrm{ABL}^{-\mathrm{ve}}$ cells. As $\mathrm{Rb}$ gene is another tumor suppressor gene which is involved in cancer development. It has been reported that hematological malignancies might be a result of dysfunction of $\mathrm{Rb}$ gene and its deletion has also been reported in a few cases [29]. Our study has shown expression of $\mathrm{Rb}$ gene in $\mathrm{BCR} / \mathrm{ABL}^{-v e}$ cells. Another tumor suppressor gene p16 is tightly controlled by the p53 gene. It promotes senescence in cells and hence can be fatal to many types of tumor cells [30]. Presence of p16 in our cells indicates normal signaling of apoptosis, which is another feature of normal cells. We have also studied Waflexpression which is a gene controlled by p53. It is involved in anti-apoptosis pathway [31]. It was localized distinctly in an organelle like structure in the cell's cytoplasm below the nucleus. So overall these studies by Immunofluorescence have clearly indicated the normality of $\mathrm{BCR} / \mathrm{ABL}^{-\mathrm{ve}}$ cell line developed from peripheral blood of CML patients and thus this cell line can be used as an additional treatment in process of BMT to cure this disease.

The data collected through these experiments suggest that the cells are likely normal and do not seem to be obnoxious in any way though derived from a patient in blast crisis of CML. These results of attaining normal MSCs are in concordance with previous studies which have reported isolation of normal MSCs from CML patients [17]. Many studies have pointed towards the use of MSCs in treating CML. They have been reported to support haematopoiesis in a study by Zhao Z [31]. They have also been proven to emolliate GHVD which is one prevalent problem in HSCT. MSCs when used in co-transplants have shown better remission in patients supporting their clinical use [20]. The use of MSCs has been lined with immunomodulatory effects in CML patients [32]. Koc and Lazarus [12] have explained the strong potentials of the use of MSCs transplants in many diseases. Recently in an International conference on Hematology and blood disorders held in US, Farid [14] has endorsed the idea that MSCs can be used for co-transplantation with HSCs in treating CML. The use of MSCs co-transplants has shown better and faster remission in patients as well as hematopoietic repopulation [12-14]. Hence, MSCs whether allogeneic or autologous, do have strong therapeutic potentials for treating this disorder in addition to BMT. There is a need to generate rigorous amount of data with large sample size and a robust biological marker profile in this area of work to come to final conclusion in using MSCs derived from CML patient's peripheral blood can be used in combination with BMT to cure this disease without much side effect. We hope that this success will give great relief to CML suffering patients in near future. 


\section{Acknowledgements}

Authors wish to thank Management of Jaslok Hospital for funding this stem cell research project number 491 and Mr. Jacob Texy for his technical help during this study.

\section{References}

1. Koretzky GA (2007) The legacy of the Philadelphia chromosome. J Clin Invest 117: 2030-2032.

2. Sawyers CL (1999) Chronic Myeloid Leukemia. N Engl J Med 341: 1330-1340.

3. Rowly JD (1973) Letter: A new consistent chromosomal abnormality in chronic myelogenous leukaemia identified by quinacrine fluorescence and Giemsa staining. Nature 1: 290-293.

4. Druker BJ, Talpaz M, Resta DJ, Peng B, Buchdunger E, et al. (2001) Efficacy and Safety of a Specific Inhibitor of the BCR/ABL Tyrosine Kinase in Rowley JD. A new consistent chromosomal abnormality Chronic Myeloid Leukemia. N Engl J Med 344: 1031-1037.

5. Kantarjian H, Giles F, Wunderle L, Bhalla K, O'Brien S, et al. (2006) Nilotinib in Imatinib-Resistant CML and Philadelphia ChromosomePositive ALL. N Engl J Med 354: 2542-2551.

6. Hughes $T$, Deininger $M$, Hochhaus $A$, Branford $S$, Radich $\mathrm{J}$, et al. (2006) Monitoring CML patients responding to treatment with tyrosine kinase inhibitors: review and recommendations for harmonizing current methodology for detecting BCR/ABL transcripts and kinase domain mutations and for expressing results. Blood 108: 28-37.

7. Cortes J, Jabbour E, Kantarjian H, Yin CC, Shan J, et al. (2007) Dynamics of BCR/ABL kinase domain mutations in chronic myeloid leukemia after sequential treatment with multiple tyrosine kinase inhibitors. Blood 110: 4005-4011.

8. Chomel JC, Bonnet ML, Sorel N, Bertrand A, Meunier MC, et al. (2001) Leukemic stem cell persistence in chronic myeloid leukemia patients with sustained undetectable molecular residual disease. Blood 118: 3657-3660.

9. Goldman JM, Apperley JF, Jones L, Marcus R, Goolden AWG, et al. (1986) Bone Marrow Transplantation for Patients with Chronic Myeloid Leukemia. N Engl J Med 314: 202-207.

10. Horowitz MM, Gale RP, Sondel PM, Goldman JM, Kersey J, et al. (1990) Graft-versus-leukemia reactions after bone marrow transplantation. Blood 75: 555-562.

11. Potdar PD, Subedi RP (2011) Defining Molecular Phenotypes of Mesenchymal and hematopoietic Stem Cells derived from Peripheral blood of Acute Lymphocytic Leukemia patients for regenerative stem cell therapy. J Stem Cells Regen Med 7: 29-40.

12. Koç ON, Lazarus HM (2001) Mesenchymal stem cells: heading into the clinic. Bone Marrow Transplantation 27: 235-239.

13. Kim EJ, Kim N, Cho SG (2013) The potential use of Mesenchymal stem cells in Hematopoietic stem cell transplantation. Exp Mol Med 45: e2.

14. Farid RJ (2013) Molecular and functional characterization of bone marrow derived mesenchymal stem cells from chronic myeloid leukemia patients. Proceedings of the International Conference on hematology and blood disorders, USA.

15. Potdar P, Sutar J (2010) Establishment and Molecular characterization of Mesenchymal Stem Cell Lines Derived from Human Visceral and Subcutaneous adipose tissues. J Stem Cells Regen Med 6: 26-35.
16. Potdar PD, Deshpande S, Chagule S (2013) Development and Molecular Characterization of Cystic Hygroma Cell Line to be used as an in vitro Model System to study the progression of Hygroma in young children. PRIJ 2013: 1-13.

17. Carrara RCV, Orellana MD, Fontes AM, Palma PVB, Kashima S, et al. (2007) Mesenchymal stem cells from patients with chronic myeloid leukemia do not express BCR-ABL and have absence of chimerism after allogeneic bone marrow transplant. Braz J Med Biol Res 2007: 57-67.

18. Lin CS, Ning $\mathrm{H}$, Lin G, Lue TF (2012) Is CD34 truly a negative marker for mesenchymal stromal cells? Cytotherapy 14: 1159-1163.

19. Zhang Y, Chai C, Jiang XS, Teoh SH, Leong KW (2012) Co-culture of umbilical cord blood CD34+ cells with human mesenchymal stem cells. Tissue Eng 12: 2161-2170.

20. Wu T, Bai H, Wang CB, Zhang Q, Tantai LF, et al. (2009) Autologous bone marrow-derived mesenchymal stem cells and peripheral blood stem cells cotransplantation in treatment of hematological malignant diseases. Zhonghua Nei Ke Za Zhi 48: 392-395.

21. Xiong YY, Fan Q, Huang F, Zhang Y, Wang Y, et al. (2014) Mesenchymal stem cells versus mesenchymal stem cells combined with cord blood for engraftment failure after autologous hematopoietic stem cell transplantation: a pilot prospective, open-label, randomized trial. Biol Blood Marrow Transplant 20: 236-242.

22. $\mathrm{Ng} \mathrm{MH} \mathrm{(2002)} \mathrm{Death} \mathrm{associated} \mathrm{protein} \mathrm{kinase:} \mathrm{From} \mathrm{regulation} \mathrm{of}$ apoptosis to tumor suppressive functions and B cell malignancies. Apoptosis 7: 261-270.

23. Nakamura S, Yokota D, Tan L, Nagata Y, Takemura T, et al. (2011) Down regulation of Thanatos-associated protein 11 by BCR ABL promotes CML cell proliferation through c-Myc expression. Int J Cancer 130: 1046-1059.

24. Rice KN, Jamieson CH (2005) Molecular Pathways to CML stem cells. Int J Hematol 91: 748-752.

25. Sun JZ, Lu Y, Xu Y, Liu F, Li FQ, et al. (2012) Epidermal growth factor receptor expression in acturemyelogenous leukemia is associated with clinical prognosis. Hematol Oncol 30: 89-97.

26. Delgado MD, Vaqué JP, Arozarena I, López-llasaca MA, Martínez C, et al. (2000) $\mathrm{H}-, \mathrm{K}$ - and N-Ras inhibit myeloid leukemia cell proliferation by a p21WAF1-dependent mechanism. Oncogene 19: 783-790.

27. Steinman RA, Huang J, Yaroslavskiy B, Goff JP, Bvall ED, et al. (1998) Regulation of p21 (WAF1) expression during normal myeloid differentiation. Blood 91: 4531-4542.

28. Li L, Wang L, Li L, Wang Z, Ho Y, et al. (2012) Activation of p53 by SIRT1 Inhibition Enhances elimiation of CML leukemia stem cells in combination with imatinib. Cancer Cell 21: 266-281.

29. Towatari M, Adachi K, Kato H, Saito H (1991) Absence of Human Retinioblastoma Gene product in the megakaryoblastic crisis of chronic myelogenous leukemia. Blood 7: 2178-2181.

30. Hernandez-Boluda JC, Cervantes F, Colomer D, Vela MC, Costa D, et al. (2003) Genomic p16 abnormalities in the progression of chronic meyloid leukemia into blast crisis: a sequential study in 42 patients. Exp Hematol 31: 204-210.

31. Zhao Z, Tang X, You Y, Li W, Liu F, et al. (2006) Assessment of bone marrow mesenchymal stem cell biological characteristics and support hemotopoiesis function in patients with chronic myeloid leukemia. Leuk Res 30: 993-1003.

32. Xishan Z, Guangyu A, Yuguang S, Hongmei Z (2011) The research on the immuno-modulatory defect of Mesenchymal Stem Cell from Chronic Myeloid Leukemic patients. J Exp Clin Cancer Res 30: 47.

Citation: Potdar PD, Lotey NK (2015) Isolation, Characterization and Application of BCR-ABL-ve Mesenchymal Stem Cells Derived from Peripheral Blood of Chronic Myeloid Leukemia (CML) in Enhancing Potentiality of Bone Marrow Transplantation in CML Patients. Cell Stem Cells Regen Med 1(1): doi http://dx.doi. org/10.16966/2472-6990.101 